\title{
Sosialisasi Adat Rasulan di Kalangan Anak-Anak pada Era Modernisasi di Daerah Playen, Gunungkidul
}

\author{
Candra Bagus Sultan Mixdam ${ }^{1}$
}

\begin{abstract}
Rasulan is a form of traditional celebration held after the harvest season ends. Rasulan is a form of gratitude to God for having bestowed joy to farmers through agricultural community Dengok village. This study aims to determine the extent of socialization apostleship done to the children so that the celebration of apostleship always carried out each year after the harvest is completed.This research is a qualitative descriptive study, the research is directed to provide symptoms, facts or events systematically and accurately on the nature of the research and analyzes based on data obtained the truth. Data collection techniques using interview and observation techniques as well as some supporting documentation. Discussion analyzed through interviews and using interpretation. Sampling techniques in the study conducted by purposive sampling, using multiple informants were selected by researchers representing each needs the support of research results. The data analysis techniques using interactive analysis model of Miles and Huberman which includes four stages of data collection, data reduction, data presentation, and conclusion.The results showed that the rasulan will always be done every year with a series of activities such as carnival village, rasul, and amusements but things do not change in the apostleship is Asum Dahar (rasul) held in petilasan eyangdamarjati with a series of events in the form of prayer and sharing of ingkung and rice to the people who attend the apostleship. Rasulan in the village Dengok in especially will always be socialized to children by the family of the most important and is supported by the community with the help of the government to socialize can run well. Children are always involved in various series of events apostleship of starting to become organizers, participants or filler series of events apostleship it is done so that the socialization of the child can be directly received by the various values of which are contained in the apostleship.
\end{abstract}

Keywords: Socialization, Customs, Rasulan, Childrens.

\footnotetext{
${ }^{1}$ Program Studi Pendidikan Sosiologi Universitas Negeri Yogyakarta

Email: candramixdam@yahoo.com
} 


\begin{abstract}
Abstrak
Rasulan merupakan bentuk dari perayaan tradisional yang dilakukan setelah masa panen selesai. Rasulan adala sebuah bentuk syukur kepada Tuhan karena telah memberikan berkah kepada petani melalui komunitas desa Dengok. Tujuan dari penelitian ini adalah untuk mengetahui sosialisasi rasulan yang dilakukan kepada anak - anak sehingga perayaan rasulan selalu dilakukan setiap tahunya setelah masa panen selesai. Penelitian ini adalah penelitian diskriptif kualitatif, penelitian diarahkan untuk menunjukan gejala, fakta atau even secara sistematis dan akurat sesuai dengan sifat penelitian dan mengalisa bersarkan data yang didapatkan. Teknik pengumpulan data menggunakan wawancara dan observasi juga menggunakan dokumentasi yang mendukung. Analisis diskusi berdasarkan wawancara dan menggunakan interpertasi. Teknik pengambilan sampling dalam penelitian ini menggunakan purposive sampling, dengan menggukan beberapa informan yang dipilih oleh peneliti untuk mewakili setiap kebutuhan data dan untuk mendukung hasil penelitian. Teknik analisis data menggunakan model analisis interaktif dari Miles dan Huberman yang meliputi empat tahap yakni, pengumpulan data, reduksi data, penyajian data dan kesimpulan.Hasil penelitian menunjukan bahwa rasulan akan tetap dilakukan setiap tahun dengan serangkaian kegiatan seperti karnaval desa, rasul dan hibutan namun hal yang tidak berubah dalam rasulan adalah Asum Dahar (rasul)dilakukan petilasan eyang Damarjati dengan serangkaian kegiatan berdoa dan berbagi ingkung serta nasi kepada orang yang mendatangi acara rasullan. Rasulan di desa Dengok secara khusus akan selalu disosialisasikan kepada anak - anak oleh keluarga peting untuk didukung oleh komunitas dengan bantuan pemerintah untuk sosialisasi tersebut berjalan dengan baik. Anak - anak selalu terlibat dalam berbagai rangkaian kegiatan rasulan yang dilakukan sehingga sosialisasi kepada anak dapat diterima secara langsung dengan berbagai nilai yang terkandung dalam rasulan.
\end{abstract}

Kata Kunci: Sosialisasi, Adat, Rasulan, Anak-anak. 


\section{PENDAHULUAN}

Perkembangan budaya setiap tahunnya mengalami peningkatan, munculnya budaya-budaya baru tidak bisa di bendung lagi, kebudayaan mencakup semuanya yang didapatkan atau dipelajari oleh manusia sebagai anggota masyarakat. Kebudayaan terdiri dari segala sesuatu yang dipelajari dari pola-pola perilaku yang normatif. Artinya, mencakup segala cara-cara atau pola-pola berpikir, merasakan, dan bertindak. Manusia sebagai pencipta sekaligus pelaku dari kebudayaan kadang akan merusak kebudayaan itu sendiri, sekarang ini banyak sekali budayabudaya yang kadang tidak cocok untuk diteruskan akan tetapi karena pengaruh dari beberapa hal maka kebudayaan tersebut tetap dilakukan, terlebih lagi kita sebagai orang timur kadang membuang budaya ketimuran kita dan digantikan dengan kebudayaan barat yang bisa kita bilang tidak sesuai dengan dasar dari kebudayaan orang timur.

Masyarakat memiliki tata cara sebagai kearifan lokal dalam setiap aktivitas di masing-masing daerah yang telah membudaya (Prasojo, 2018). Salah satu bentuk dari kebudayaan adalah tindakan yang dilakukan oleh individu atau masyarakat bentuk tindakan tersebut salah satunya adalah upacara adat yang dimiliki oleh suatu kelompok tertentu upacara adat adalah suatu upacara yang dilakukan secara turun-temurun yang berlaku di suatu daerah.

Gunung kidul merupakan salah satu daerah yang masih memegang erat hal-hal yang bersifat kebudayaan salah satunya adalah upacara adat, upacara adat yang sampai sekarang masih tetap dilakukan setiap tahunnya adalah rasulan. Dalam pelaksanaan tradisi rasulan tersebut, setiap desa yang ada di daerah Gunungkidul memiliki wewenang tersendiri untuk menentukan kapan dan bagaimana mereka akan melaksanakan tradisi rasulan. Akan tetapi yang membuat rasulan sama adalah di mana arti dari rasulan itu sendiri yaitu merupakan bentuk rasa syukur kepada tuhan atas rezeki yang telah dilimpahkan pada masyarakat desa.

Dimulai dari masa kanak-kanak, masa kanak-kanak biasanya akan menjadi ukuran apakah mereka akan mengembangkan atau mempertahankan budaya dan upacara-upacara adat ataukah mereka 
meninggalkannya dan berganti dengan mengembangkan dan menciptakan budaya baru, di daerah playen, Gunungkidul khususnya Dusun Dengok IV sosialisasi tentang rasulan terus di berikan kepada anak-anak sebagai penerus yang akan melestarikan rasulan, berbagai bentuk sosialisasi diberikan kepada anak-anak supaya anak-anak akan tertarik untuk mengikuti kegiatan rasulan dan juga diharapakan dapat mengerti arti dari rasulan yang di dalamnya terdapat nilai-nilai yang akan sangat membantu anak-anak tersebut dalam menjalani hidup mereka di dalam masyarakat.

\section{METODE PENELITIAN}

Penelitian ini menggunakan metode penelitian deskriptif kualitatif. Penelitian dilaksanakan saat pelaksanaan sebelum asum dahar setelah asum dahar dan sesudah asum dahar dilakukan. Dalam pengambilan data, peneliti melakukan wawancara, pengamatan serta dokumentasi di Dusun Dengok IV sebagai lokasi penelitian tentang rasulan. Dalam penelitian ini, peneliti memlilih informan dengan menggunakan teknik purposive sampling. Teknik pengumpulan data yang dilakukan dalam penelitian ini adalah dengan wawancara, observasi dan dokumentasi. Peneliti melakukan observasi atau mengamati secara langsung di Dusun Dengok IV sebagai tempat berlangsungnya acara rasulan. Dalam memeriksa keabsahan data, peneliti melakukannya dengan triangulasi data, pengumpulan data dan analisis data akan terus dilakukan sampai data memiliki titik jenuh dengan arti data yang didapatkan sudah memiliki banyak kesamaan. Teknik analisis data dalam penelitian ini dilakukan secara interaktif sebagaimana yang diajukan oleh Milles dan Huberman yang terdiri dari tiga aspek: Reduksi Data (Data Reduction), Penyajian Data (Data Display), Penarikan Kesimpulan (Conclusions Drawing/Verifications).

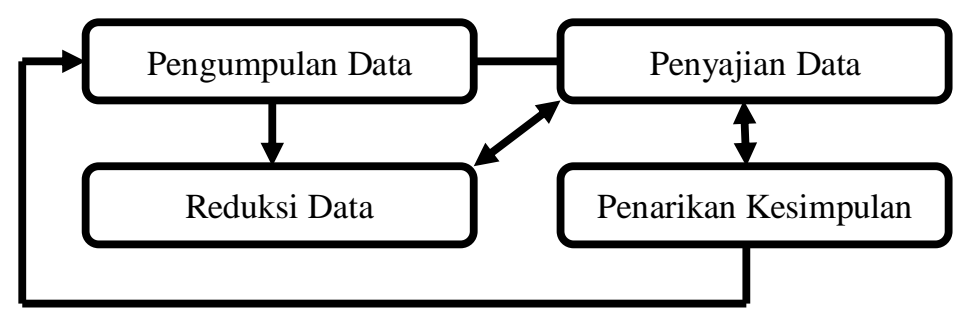

Bagan 1: Model Interaktif Miles dan Huberman 


\section{HASIL DAN PEMBAHASAN}

Pada hari sabtu tanggal 24 Mei 2014 awal rangkaian kegiatan rasulan dimulai dengan acara kirab yang diikuti oleh seluruh dusun di Desa Dengok. Pengertian kirab secara umum adalah berjalan bersama-sama dan beriringiringan secara teratur dan berurutan dari awal sampai akhir yang dilaksanakan dalam upacara adat atau tradisi kirab.

Pada hari minggu tgl 25 Mei 2014 warga Desa Dengok IV melaksanakan rasulan, Desa Dengok IV yang digunakan sebagai tempat wilayah penelitian melaksanakan acara rasulan atau warga Desa Dengok IV sering menyebutnya Asum Dahar, prosesi Asum Dahar ini berlangsung di petilasan Eyang Damarjati yang masuk dalam wilayah Dusun Dengok IV, petilasan Eyang Damarjati selalu digunakan saat prosesi rasul atau biasa disebut Asum Dahar berlangsung, dan hak tersebut telah menjadi ciri khas dari rasulan warga Desa Dengok IV yang mana berbeda dari proses rasulan yang dilakukan oleh dusun-dusun yang lain yang masuk pada wilayah Desa Dengok. Biasanya proses rasulan yang dilakukan oleh dusun-dusun lain yang ada di Desa Dengok hanya diselenggerakan di pendopo dusun saja sedangkan di Dengok IV dilakukan di petilasan Eyang Damarjati. prosesi Asum Dahar berlangsung sekitar pukul 13.00, warga berkumpul di petilasan Eyang Damarjati dengan membawa nasi serta ingkung yang dimasukan dalam wadah yang terbuat dari anyaman bambu, tidak setiap warga mengumpulkan nasi dan ingkung, hanya beberapa warga atau kepala keluarga saja, karena nasi dan ingkung tersebut nantinya akan dibagikan kepada warga-warga yang sudah datang di petilasan Eyang Damarjati, sebelum nasi dan ingkung tersebut dibagikan beberapa sambutan diberikan oleh Kepala Desa dan Kepala Dinas Pariwisata Gunung Kidul, setelah sambutan juru kunci memimpin doa sebelum nasi dan ingkung tersebut dibagikan kepada warga yang telah menunggu di petilasan Eyang Damarjati, warga yang datang bukan hanya dari warga Dengok IV saja akan tetapi dihadiri oleh masyarakat lain yang datang dari luar wilayah Desa Dengok bahkan ada juga yang datang dari luar kota untuk melihat prosesi rasulan atau asum dahar berlangsung, hal tersebut dikarenakan ketertarikan mereka pada tradisi adat kebudayaan yang masih dilestarikan.

Pada hari minggu sore hari serta malam senin pemuda-pemuda yang berasal dari Dengok IV menampilkan ketoprak, ketoprak merupakan pertunjukan yang dimainkan oleh beberapa individu dengan peran dan 
sifatnya yang telah ditentukan. Biasanya ketoprak menceritakan tentang kisah-kisah jaman dahulu akan tetapi tetap ada unsur zaman moderen. Jika ketoprak yang ditampilkan oleh warga Dusun Dengok IV ini mulai dari kostum hingga gaya bahasa. Wayang kulit sebagai acara penutup rangkaian kegiatan rasulan.

\section{Sosialisasi Upacara Adat Rasulan di Kalangan Anak Anak-Anak}

Sosialiasi yang dilakukan kepada anak-anak oleh keluarga yang paling utama serta masyarakat dan juga di dukung oleh pemerintah harus melalu proses komunikasi serta interaksi yang memenuhi atau bisa dikatakan yang sesuai dengan anak-anak karena kepribadian anak-anak berbeda makan proses sosialisasi tersebut juga akan berbeda-beda pada setiap anak.

\section{Agen Sosialisasi Adat Rasulan}

Peran dalam mensosialisasikan rasulan kepada anak-anak dilakukan oleh berbagai unsur dari mulai keluarga, masyarakat, pemerintah dan juga lembaga pendidikan. Semua bekerja sama dalam melakukan sosialisasi kepada anak-anak supaya anak-anak dapat memahami arti dari rasulan dan setelah memahami serta antusias maka anak-anak akan terus menjaganya saat mereka diberikan tanggung jawab untuk terus melakukan rasulan setiap tahunnya.

\section{Jenis-Jenis Sosialisasi Rasulan}

Sosialisasi primer adalah sosialisasi yang pertama dijalani individu semasa kecil dan menjadi pembuka bagi seseorang memasuki keanggotaan dalam masyarakat. Sosialisasi primer pertama kali dilakukan oleh keluarga. Anakanak yang lahir di Desa Dengok IV diberikan penanaman nilai sejak dini tentang kebudayaan yang dimilikinya, orang tua memberikan kesempatan kepada anak-anak mereka untuk mengenal kebudayaan yang mereka miliki, nilai-nilai yang ada pada masyarakat sekitar mereka tinggal dan juga agama yang akan mereka anut kelak sebagai landasan hidup mereka.

Sosialisasi sekunder adalah proses sosialisasi berikutnya yang memperkenalkan kepada individu tersebut sektor-sektor baru dunia objektif masyarakat. Sosialisasi sekunder mengajarkan nilai-nilai baru di luar lingkungan keluarga seperti di lingkungan sekolah, lingkungan bermain, dan lingkungan kerja. Anak-anak pada Desa Dengok masih sangat kental kekerabatannya antara teman dan masyarakat jadi masyarakat mengawasi 
anak-anak mereka dalam hal memahami nilai dan norma yang ada di lingkungan masyarakat di mana anak mereka berada, kontrol dari teman dekat ataupun masyarakat masih tetap terjaga masih selalu berjalan sesuai fungsinya.

\section{Nilai-Nilai Sosialisasi Rasulan}

Dalam rasulan terdapat beberapa nilai yang bisa dipelajari oleh anak-anak saat mereka mendapatkan sosialisasi, anak-anak serta masyarakat yang ikut dalam rangkaian rasulan diharapakan untuk menerima beberapa nilai seperti tanggu jawab, gotong royong, kesabaran serta keikhlasan yang akan mereka gunakan untuk menjalani kebutuhan hidup, nilai-nilai tersebut juga akan sangat membantu individu yang mempelajarinya untuk beradaptasi dengan masyarakat pada umumnya.

\section{Dampak Sosialisasi Rasulan}

Sosialisasi adalah sebuah proses yang dialamai oleh setiap manusia di mana seseorang yang sedang melakukan proses sosialisasi akan mengenal apa yang ada dalam masyarakat termasuk nilai, norma dan juga perilaku. Ketika melakukan proses sosialisasi dalam masyarakat ini tentunya akan menimbulkan beberapa dampak atau pengaruh bagi orang yang melakukan proses sosialisasi tersebut. Dampak sosial dari rasulan yaitu anak-anak akan semakin mengetahui nilai-nilai yang terkandung di dalam lingkungan di mana mereka tinggal, dampak ekonomi dari rasulan berhubungan dengan para pedagang yang mendapatkan tambahan ekonomi saat berjualan di area diadakannya rasulan yang ramai dengan orang, sedangkan dampak budaya yaitu anak-anak akan menjaga budaya mereka serta memberikan inofasiinofasi untuk membuat rasulan lebih menarik walaupun hal-hal inti dari rasulan akan tetap mereka jaga.

Selain itu rasulan juga memberikan dampak baik dampak positif ataupun negatif, dampak positif dari rasulan yaitu tertanamnya nilai-nilai yang ada dalam kegiatan rasulan yang akan mereka gunakan untuk menjalani hidup, sedangkan dampak negatif dari rasulan terdapat dari masyarakat dalam atau luar yang belum sadar akan kebersihan, mereka membuang sampah di area tempat berlangsungnnya rasulan, solusi yang di berikan dari hal tersebut adalah panitia kegiatan rasulan setelah selesai rasulan akan membersihkan sampah-sampah yang berserakan dibantu 
beberapa warga yang telah memiliki kesadaran tentang kebersihan lingkungan.

\section{KESIMPULAN}

Proses upacara adat rasulan di Desa Dengok, Playen, Gunung Kidul dilakukan dengan cara yang tidak sama, khususnya di Dusun Dengok IV. Rasulan dilaksanakan di petilasan Eyang Damarjati dan itu hanya terdapat di Dusun Dengok IV, di dalam rasulan sendiri di isi dengan doadoa yang di panjatkan kepada Tuhan setelah mereka selesai berdoa maka para warga yang datang akan diberikan ingkung serta nasi dan akan mereka makan bersama-sama.

Orang tua memiliki andil yang sangat besar terhadap sosialisasi kepada anak akan pentingnya melestarikan budaya rasulan, yakni dengan cara orang tua mengajarkan anak mereka bagaimana cara menghargai dan menjaga budaya yang mereka miliki, orang tua memberikan arahan bagaimana proses upacara adat rasulan berlangsung, serta orang tua memberikan pengertian akan makna dan pentingnya melaksanakan dan mengikuti upacara adat rasulan. Hal tersebut membuat anak-anak mengerti bahwa mereka memiliki tradisi kebudayaan yang harus selalu mereka jaga dan terangsang untuk mengikuti kegiatan upacara adat rasulan di desanya. Tidak hanya orang tua yang berperan aktif untuk mensosialisasikan budaya rasulan, warga setempat, teman bergaul dan pemerintah juga berperan penting dalam upaya pelestarian budaya rasulan. Adapun rekomendasi dari penulis yaitu: 1) bagi masyarakat desa Dengok khususnya lebih menjaga prosesi adat rasulan yang akan di turunakan kepada generasi-generasi penerus yang akan menjadi tonggak dari pelestarian adat budaya yang mereka miliki; 2) bagi pemerintah bahwasanya dukungan dari pemerintah sangat dibutuhkan untuk keberlangsungan adat kebudayaan yang di miliki oleh daerah tertentu sehingga daerah tersebut memiliki keunikan yang menjadi ciri khas mereka; 3) bagi anak-anak muda sebagai penerus tongkat estafet pelestarian kebudayaan maka harus lebih masuk kedalam sistem kebudayaan tersebut sehingga akan memahami nilai-nilai dan norma yang terkandung dalam adat istiadat rasulan. 


\section{DAFTAR PUSTAKA}

Arikunto, Suharsimi. (2006). Prosedur Penelitian: Suatu Pendekatan Praktek, Edisi Revisi, PT, Rineka Cipta, Jakarta.

Bungin, Burhan. (2008). Penelitian Kualitatif. Jakarta: Kencana.

Herdiansyah, Haris. (2010). Metodologi Penelitian Kualitatif Untuk Ilmuilmu Sosial. Jakarta: Salemba Humanika.

Khairuddin. (2008). SosiologiKeluarga. Yogyakarta: Liberty.

Koentjaraningrat. (1984). Kebudayaan Mentalitas dan Pembangunan. Jakarta: PT. Gramedia.

Miles, Matthew B. \& A. Michael Huberman. (1992). Analisis Data Kualitatis. Jakarta: Universitas Indonesia Press.

Moeleong, L. (2004). Metode Penelitian Kualitatif. Bandung: Remaja Rosdakarya.

Muhidin, Syarif. (1981). Pengantar Kesejahteraan Sosial. Bandung: Penerbit STKS.

Prasojo, M. N. B. (2018). Konstruksi Sosial Masyarakat Terhadap Alam Gunung Merapi: Studi Kualitatif tentang Kearifan Lokal yang Berkembang di Desa Tlogolele Kecamatan Selo Kabupaten Boyolali. Jurnal Analisa Sosiologi, 4(2).

Ritzer dan Goodman. (2010). Teori Sosiologi. Yogyakarta: Kreasi Wacana.

Salim, Agus. (2006). Teori dan Paradigma Penelitian Sosial. Yogyakarta: Tiara Wacana.

Soelaeman, M. (2009). Ilmu Sosial Dasar.Bandung: PT Refika Aditama.

Sugiyono. (2011). Metode Penelitian Kuantitatif, Kualitatif dan R\&D. Bandung: Alfabeta.

W. Gulo. (2004). Metodologi Penelitian. Jakarta: Grasindo. 